\title{
Optimal Utilization of Test Facilities to Replicate Operational Environments
}

\author{
Timothy W. Hoy, U.S. Army Aberdeen Test Center \\ Jeffrey W. Herrmann, Department of Mechanical Engineering, University of Maryland
}

\begin{abstract}
Useful system endurance tests require operating a system in settings similar to operational environments. However, existing test facilities may not be good replicas of the operational environment, especially for systems with long life cycles that are being used in new and unforeseen situations. Because constructing new test facilities can be expensive and timeconsuming, it is desirable to use the existing test infrastructure to replicate the operational environment as closely as possible. This study presents an optimization model that determines the most appropriate amount of testing to conduct using each existing test facility. A multi-objective model is also presented, and the application of this work to two military vehicle tests is discussed.
\end{abstract}

\section{KEYWORDS}

Test planning, test optimization, automotive applications, vehicle reliability, durability testing, military

\section{INTRODUCTION}

Testing is an important part of a system development life cycle. To develop complex systems, many different types of testing are done, including performance tests and endurance tests. For more about system testing, see Blanchard and Fabrycky. ${ }^{1}$

Useful endurance tests require operating a system in settings similar to the expected operational environment. However, existing test facilities may not be good replicas of the operational environment, especially for systems with long life cycles that are being modified for use in new and unforeseen situations, as in the case of military vehicles. Because constructing new test facilities can be expensive and time-consuming, it is desirable to use the existing test infrastructure to replicate the new operational environment as closely as possible. But a new test plan is required, because the old test plans were designed to replicate environments that are no longer relevant. Consider, for instance, using a test plan developed soon after World War II for testing trucks that, 60 years later, will be driving not on the streets of European cities but instead on highways through the Middle Eastern countryside. For more information on military vehicle test planning, see Hoy. ${ }^{2}$

In this study, an optimization approach is considered for designing test plans relevant to an operational environment. When a system runs in the operational environment or in an existing test facility, it generates a number of behaviors that are measurable and related to the overall performance of the system. For instance, in a vehicle, such behaviors may include transmission temperature and roll rate, because they indicate how hard the vehicle is working and what types of stresses it is undergoing. Since any given behavior is dynamic, the distribution of each behavior over a domain of relevant values will be considered. The distribution indicates how much time each behavior remains at a particular value. Relevant behaviors will be used to characterize test facilities and the operational environment, and the difference between those behaviors will be measured as a way to determine the differences between the test facilities and the operational environment. 
Some methods for designing better vehicle tests have been presented, though none address the problem of using existing test infrastructure to replicate an operational environment. Kouta and Play ${ }^{3}$ sought to optimize vehicle endurance testing by "building" new test paths for prototype vehicles using the correlation methods of mechanical loadings and mechanical damage. The researchers determined a means to relate and visualize the connection between damage frequency and course loading-profile geometry.

Huizinga et al., ${ }^{4}$ after studying automotive endurance and fatigue life testing, argued that accurate analysis of vehicle endurance and component life is better obtained through computer-aided engineering methods. Rather than addressing shortcomings in physical endurance testing, the researchers developed a method by which finite element analysis and fatigue life analysis can, in some cases, replace certain costly and lengthy road tests.

This study presents an optimization model that determines the most appropriate amount of testing to conduct using each existing test facility. A multi-objective model is described as well. Finally, this study discusses the application of this work to two military vehicle tests.

\section{PROBLEM DESCRIPTION}

The considered system requires an endurance test, during which the system will be operated for a fixed total amount of time. Distributions are given regarding one or more behaviors of the system in the operational environment and distributions regarding those same behaviors for each test facility. Such information may be available from the evaluation of a previous, similar version of the system. The test facilities provide different testing conditions under which the system can be operated; the facilities do not perform different types of tests.

A test plan specifies how much time the system should operate at each test facility. The aggregate behavior distribution will then predict how much time a behavior remains at a particular value. The problem is to design the test plan so as to minimize the difference between the aggregate behavior distribution and the behavior distribution from the operational environment.

\section{PROBLEM FORMULATION}

There are $N$ test facilities and $I$ system behaviors. To describe the distribution of behavior $i$, the domain of values for behavior $i$ was partitioned using $J$ values $\mathrm{a}_{i 1}, \ldots, \mathrm{a}_{i j}$; it was determined that $\mathrm{a}_{i 0}=0$. That created $J$ intervals. Then, for $j=1, \ldots, \mathrm{J}, y_{i j}$ was identified as the fraction of the time that behavior $i$ registered a value between $a_{i j-1}$ and $a_{i j}$ in the operational environment, and $x_{n i j}$ was the fraction of the time that behavior $i$ logged a value between $a_{i j-1}$ and $a_{i j}$ in test facility $n$. In practice, it will be common for the $a_{i j}$ to be uniformly spaced, but it is not necessary. All of the $y_{i j}$ and $x_{n i j}$ are non-negative and satisfy the following constraints:

$$
\begin{aligned}
& \sum_{j=1}^{J} y_{i j}=1, \forall i=1, \ldots, I \\
& \sum_{j=1}^{J} x_{n i j}=1, \forall i=1, \ldots, I ; n=1, \ldots, N
\end{aligned}
$$


The decision variables reflect the relative amounts of time that the system is tested using each test facility, which are denoted by $w_{1}, \ldots, w_{N}$. W denotes the vector $\left(w_{1}, \ldots, w_{N}\right)$, where the $w_{n}$ are non-negative and satisfy the following constraint:

$$
\sum_{n=1}^{N} w_{n}=w_{1}+\cdots+w_{N}=1
$$

The aggregate behavior distribution for each behavior is the weighted sum of the behavior distributions for each test facility. The function $f_{i}(W)$ measures the error between the aggregate behavior distribution and the distribution in the operational environment:

$$
f_{i}(W)=\sqrt{\sum_{j=1}^{J}\left(\sum_{n=1}^{N} w_{n} \cdot x_{n i j}-y_{i j}\right)^{2}}
$$

Given these preliminaries, the optimization problem for behavior $i$ can be formulated as follows:

$$
\begin{array}{ll}
\text { Minimize } & f_{i}(W)=\sqrt{\sum_{j=1}^{J}\left(\sum_{n=1}^{N} w_{n} \cdot x_{n i j}-y_{i j}\right)^{2}} \\
\text { Subject to: } & \sum_{n=1}^{N} w_{n}=1 \\
& w_{n} \geq 0 ; n=1: N
\end{array}
$$

In addition, a bi-objective version can be formulated by considering two behaviors at the same time. This action will yield a set of non-dominated solutions from which the decision-maker can select a solution. In addition, the objectives could be combined using a type of weighted sum. ${ }^{5}$

\section{EXAMPLE}

To clarify the problem, here is a simple, hypothetical example with two test facilities, two behaviors, and three intervals for each domain.

Table 1 lists the behavior distributions for two test facilities and the operational environment. This shows that, in Facility 1, 25\% of the time behavior 1 attains values between 0 and 10, 50\% of the time behavior 1 attains values between 10 and 20, and 25\% of the time behavior 1 attains values between 20 and 30. Likewise, Table 2 gives the behavior distributions for behavior 2 . 
Table 1. Behavior 1 distribution.

\begin{tabular}{|c|c|c|c|c|}
\hline & $\left.\boldsymbol{a}_{\mathbf{1 j}-\mathbf{1}}, \boldsymbol{a}_{\mathbf{1 j}}\right)$ & $\begin{array}{c}\text { Facility 1 } \\
\boldsymbol{x}_{\mathbf{1 1}}\end{array}$ & $\begin{array}{c}\text { Facility 2 } \\
\boldsymbol{x}_{\mathbf{2 1}}\end{array}$ & $\begin{array}{c}\text { Operational } \\
\text { environment } \\
\boldsymbol{y}_{\mathbf{1 j}}\end{array}$ \\
\hline 1 & $(0,10)$ & 0.25 & 0.4 & 0.3 \\
\hline 2 & $(10,20)$ & 0.5 & 0.4 & 0.5 \\
\hline 3 & $(20,30)$ & 0.25 & 0.2 & 0.2 \\
\hline
\end{tabular}

Table 2. Behavior 2 distribution.

\begin{tabular}{|c|c|c|c|c|}
\hline $\boldsymbol{j}$ & $\left(\boldsymbol{a}_{\mathbf{2}-\mathbf{1}}, \boldsymbol{a}_{\mathbf{2}}\right)$ & $\begin{array}{c}\text { Facility 1 } \\
\boldsymbol{x}_{\mathbf{1 2}}\end{array}$ & $\begin{array}{c}\text { Facility 2 } \\
\boldsymbol{x}_{\mathbf{2} \boldsymbol{j}}\end{array}$ & $\begin{array}{c}\text { Operational } \\
\text { environment } \\
\boldsymbol{y}_{\mathbf{2}}\end{array}$ \\
\hline 1 & $(200,300)$ & 0.25 & 0.2 & 0.3 \\
\hline 2 & $(300,400)$ & 0.3 & 0.6 & 0.5 \\
\hline 3 & $(400,500)$ & 0.45 & 0.2 & 0.2 \\
\hline
\end{tabular}

Assuming that $w_{1}=0.1$ and $w_{2}=0.9$, the aggregate behavior distribution for behavior 1 can be determined. The system is in Facility 1 for $10 \%$ of the total time, and $25 \%$ of that time, behavior 1 attains values between 0 and 10. The system is in Facility 2 for $90 \%$ of the total time, and $40 \%$ of that time, behavior 1 attains values between 0 and 10. Thus, the first component of the aggregate behavior distribution for behavior 1 equals $25 \%(10 \%)+40 \%(90 \%)=2.5 \%+36 \%$ $=38.5 \%$. The other components are calculated in the same manner, and the complete aggregate behavior distribution for behavior 1 is $(0.385,0.41,0.205)$. The error function $f_{1}(0.1,0.9)=$ 0.1239 . Likewise, the aggregate behavior distribution for behavior 2 is $(0.205,0.57,0.225)$, and the error function $f_{2}(0.1,0.9)=0.1206$. Figure 1 shows how the two error functions change as the weights $w_{1}$ and $w_{2}$ change, demonstrating that test plans close to $(0,1)$ or $(1,0)$ are dominated by intermediate test plans. Among those intermediate test plans, there is a trade-off between the two error functions: reducing one requires increasing the other.

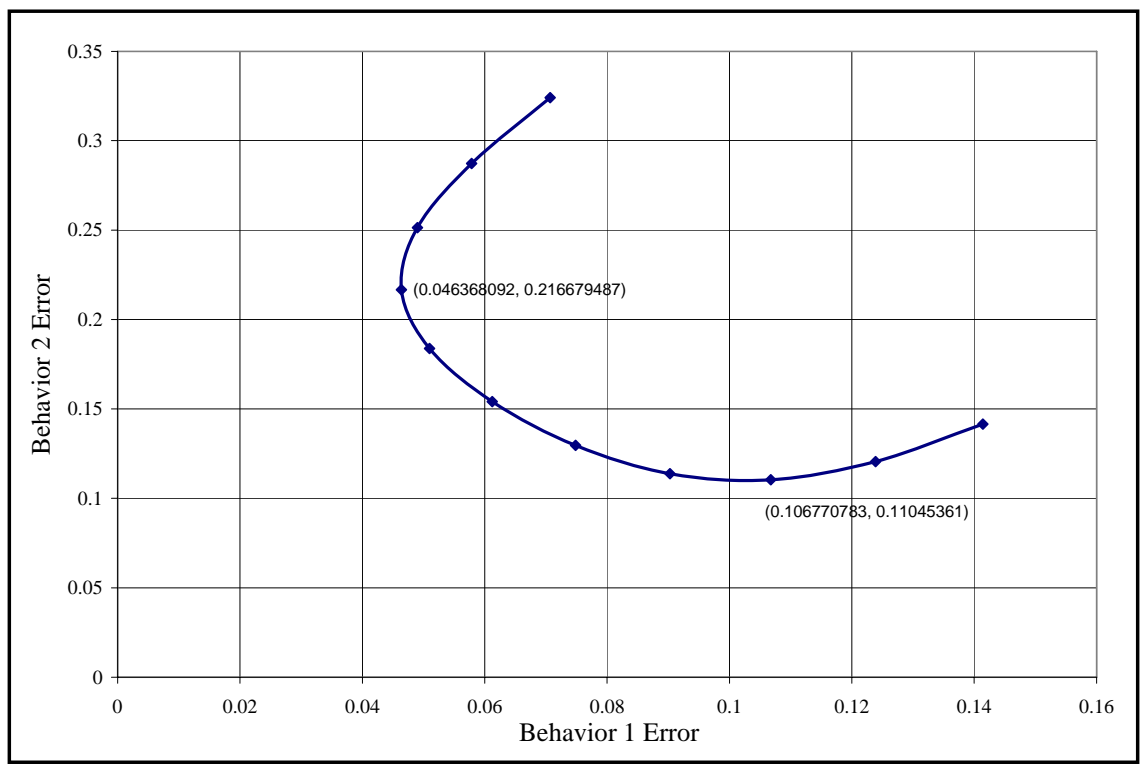

Figure 1. Error function values for different weight values. 


\section{MILITARY VEHICLE TESTING}

The U.S. Army Aberdeen Test Center (ATC), located at the Aberdeen Proving Ground (APG) in Aberdeen, Maryland, is the leading developmental test facility in the Department of Defense (DOD). As shown in Table 3, ATC has more than 30 miles of test courses that provide a wide range of endurance testing conditions for any size and type of wheeled or tracked vehicle. ${ }^{6}$

Typically, vehicles undergo 12,000- to 20,000-mile endurance tests on these courses. For primary roads, vehicles run on level and hilly paved roads at speeds up to 65 miles per hour (mi/hr). For secondary roads, vehicles run on an assortment of gravel, cobblestone, level, and hilly country roads. For cross-country terrains, vehicles run on hilly and level courses that are full of large potholes and steep hills and valleys.

Table 3. ATC road courses frequently used for endurance tests.

\begin{tabular}{|c|c|c|c|}
\hline & Road Courses & $\begin{array}{c}\text { Length } \\
\text { km (mi) }\end{array}$ & Description/Intended Purpose \\
\hline \multirow{2}{*}{ 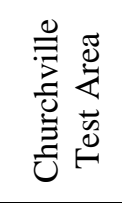 } & CTA-B & $11.9(7.4)$ & $\begin{array}{l}\text { Hilly cross-country road course/to provide } \\
\text { engine and powertrain testing (built 1942) }\end{array}$ \\
\hline & CTA-C & $2.4(1.5)$ & $\begin{array}{l}\text { Hilly secondary road course/to provide } \\
\text { engine and powertrain testing for trailers and } \\
\text { semi-trailers (built 1942) }\end{array}$ \\
\hline \multirow{6}{*}{ 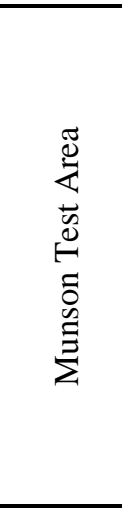 } & Gravel & $3.2(2.0)$ & $\begin{array}{l}\text { Compacted bank gravel, improved } \\
\text { secondary road course }\end{array}$ \\
\hline & Belgian Block & $1.2(0.75)$ & $\begin{array}{l}\text { Granite blocks in concrete/to simulate } \\
\text { European road conditions }\end{array}$ \\
\hline & Imbedded Rock & $0.24(0.15)$ & $\begin{array}{l}\text { Granite stones in concrete/to provide tire } \\
\text { and suspension testing }\end{array}$ \\
\hline & $\begin{array}{c}\text { 2-inch } \\
\text { Washboard }\end{array}$ & $0.25(0.16)$ & $\begin{array}{l}\text { Concrete/to provide high-frequency testing } \\
\text { of vehicle suspension system }\end{array}$ \\
\hline & $\begin{array}{l}\text { 3-inch Spaced } \\
\text { Bump }\end{array}$ & $0.23(0.14)$ & $\begin{array}{l}\text { Concrete/to provide repeatable high- } \\
\text { amplitude suspension system testing }\end{array}$ \\
\hline & Wave Course & $0.14(0.08)$ & $\begin{array}{l}\text { Concrete/to provide high-amplitude vehicle } \\
\text { frame twisting }\end{array}$ \\
\hline \multirow{7}{*}{ 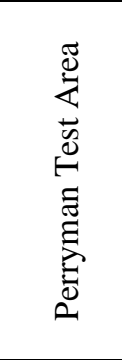 } & PTA-1 & $8.4(5.2)$ & Moderate severity cross-country course \\
\hline & PTA-2 & $2.9(1.8)$ & Moderately rough cross-country course \\
\hline & PTA-3 & $5.3(3.3)$ & Rough cross-country course \\
\hline & PTA-4 & $4.0(2.5)$ & Severe cross-country course, natural marsh \\
\hline & PTA-A & $3.9(2.4)$ & Unimproved native soil secondary road \\
\hline & PTA-B & $5.1(3.2)$ & $\begin{array}{l}\text { Unimproved gravel and crushed stone } \\
\text { secondary road }\end{array}$ \\
\hline & Paved & $6.1(3.8)$ & High-speed primary paved road \\
\hline \multicolumn{2}{|c|}{ Mile Loop } & $1.6(1.0)$ & $\begin{array}{l}\text { Level concrete course for continuous high- } \\
\text { speed operation tests (built 1933) }\end{array}$ \\
\hline
\end{tabular}

\section{VEHICLES}

This study examined two specific cases: the M915 truck tractor and the M1114 high mobility multipurpose wheeled vehicle (HMMWV). The circumstances for these two vehicles were quite similar. Both vehicles had previously satisfied all developmental and operational testing requirements before being fully fielded and are now in the operation and support phase. ${ }^{7,8}$ However, both vehicles needed automotive endurance testing at ATC for the development of new 
components to be deployed in Operation Iraqi Freedom (OIF), and both were part of a project that used an advanced distributed modular acquisition system (ADMAS) to collect data from certain vehicles being used in OIF. Data was obtained from 30 days of operation in the current theatre.

The M915 was designed to be an over-the-road tractor-trailer meant to haul heavy or large cargos long distances over improved terrain. The HMMWV was intended primarily to traverse rugged cross-country terrain, such as battlefields, at low to moderate speeds carrying passengers instead of cargo. The standard HMMWV road course test matrix, which is still in use, was developed in the early 1980s when the HMMWV was just entering its acquisition process. The M915 truck tractor has been around longer, and its road course test matrix was developed during the 1970s. Initial endurance testing of both vehicles focused on road conditions such as cobbled streets, poorly maintained paved roads, some highways, and gravel or mud secondary roads.

\section{TEST PLAN DEVELOPMENT}

Because no single road course at ATC is a close match to the conditions experienced in OIF, the test plan requires a combination of ATC road courses. It was clear that a new test plan was needed due to the new operational environment.

A test plan optimization model was formulated to determine the road course test plan that best fit the operational environment. Data is available about vehicle performance in OIF and on ATC road courses, including the distributions of road speed; vertical, longitudinal, and lateral accelerations; engine load; throttle position; fuel consumption rate; roll, pitch, and yaw rate; coolant temperature; transmission oil temperature; engine speed; and transmission output speed.

The optimization model determined the optimal fraction of time to spend on each course. Because a road course test matrix uses mileage to describe a test plan, it was necessary to convert the time fraction into a distance fraction. The mileage accumulated for each data file and road course would gain special importance later, when it became necessary to convert the percentage of time spent on a course to the percentage of miles spent on each course.

In order to convert the $w_{n}$ vector from the time domain into a distance for the road course test matrix so the total across all courses equaled $T$ (the desired total), the average vehicle speed $V_{n}$ for each course was used to convert time to miles and was then normalized. For course $n$, the distance $d_{n}$ on that course can be calculated as follows:

$$
d_{n}=\frac{w_{n} V_{n} T}{w_{1} V_{1}+\cdots+w_{N} V_{N}}
$$

\section{RESULTS}

Based on concerns raised by units serving in the OIF theatre, road speed was chosen as the most significant behavior, and that data was used in the optimization model to create a more relevant test plan. The resulting single-objective optimal road course test plan is shown in the second data column of Table 4. Figure 2 shows the road speed distributions for the actual operational environment, the standard M915 test plan, and the single-objective optimal plan as well as the dual-objective optimal plan, which will be discussed later. In the optimal singleobjective road course test plan, the vehicle spends more time traveling at low speeds (less than $30 \mathrm{mi} / \mathrm{hr}$ ), which more closely (though not perfectly) matches the operational environment. 
Table 4. Comparison of the standard, single-objective optimal, and dual-objective optimal road course test plans for the M915.

\begin{tabular}{|l|c|c|c|}
\hline \multirow{2}{*}{ Test Course } & \multicolumn{3}{|c|}{ Distance per course, km (mi) } \\
\cline { 2 - 4 } & $\begin{array}{c}\text { Standard } \\
\text { Plan }\end{array}$ & $\begin{array}{c}\text { Single-objective } \\
\text { Optimal Plan }\end{array}$ & $\begin{array}{c}\text { Dual- } \\
\text { objective } \\
\text { Optimal Plan }\end{array}$ \\
\hline Paved & $\mathbf{1 2 0 7 ( 7 5 0 )}$ & $\mathbf{6 9 2 ( 4 3 0 )}$ & $\mathbf{4 0 2 ( 2 5 0 )}$ \\
\hline Secondary Roads & $\mathbf{3 3 5 ( 2 0 8 )}$ & $\mathbf{8 2 1 ( 5 1 0 )}$ & $\mathbf{9 1 7}(\mathbf{5 7 0})$ \\
\hline MTA Gravel & $134(83)$ & & $193(120)$ \\
\hline MTA BB/G & $53(33)$ & & $531(330)$ \\
\hline CTA-C & $148(92)$ & $612(380)$ & $193(120)$ \\
\hline PTA-A & & $209(130)$ & \\
\hline Cross-Country & $\mathbf{6 7}(\mathbf{4 2})$ & $\mathbf{9 6}(\mathbf{6 0})$ & $\mathbf{2 9 0}(\mathbf{1 8 0})$ \\
\hline PTA-1 & $67(42)$ & & $258(160)$ \\
\hline MTA 2” Bumps & & $96(60)$ & $32(20)$ \\
\hline Total & $\mathbf{1 6 0 9 ( 1 0 0 0 )}$ & $\mathbf{1 6 0 9}(\mathbf{1 0 0 0 )}$ & $\mathbf{1 6 0 9}(\mathbf{1 0 0 0})$ \\
\hline Error (norm) & $\mathbf{0 . 2 6 7}$ & $\mathbf{0 . 1 3 5}$ & $\mathbf{0 . 1 7 8}$ \\
\hline
\end{tabular}

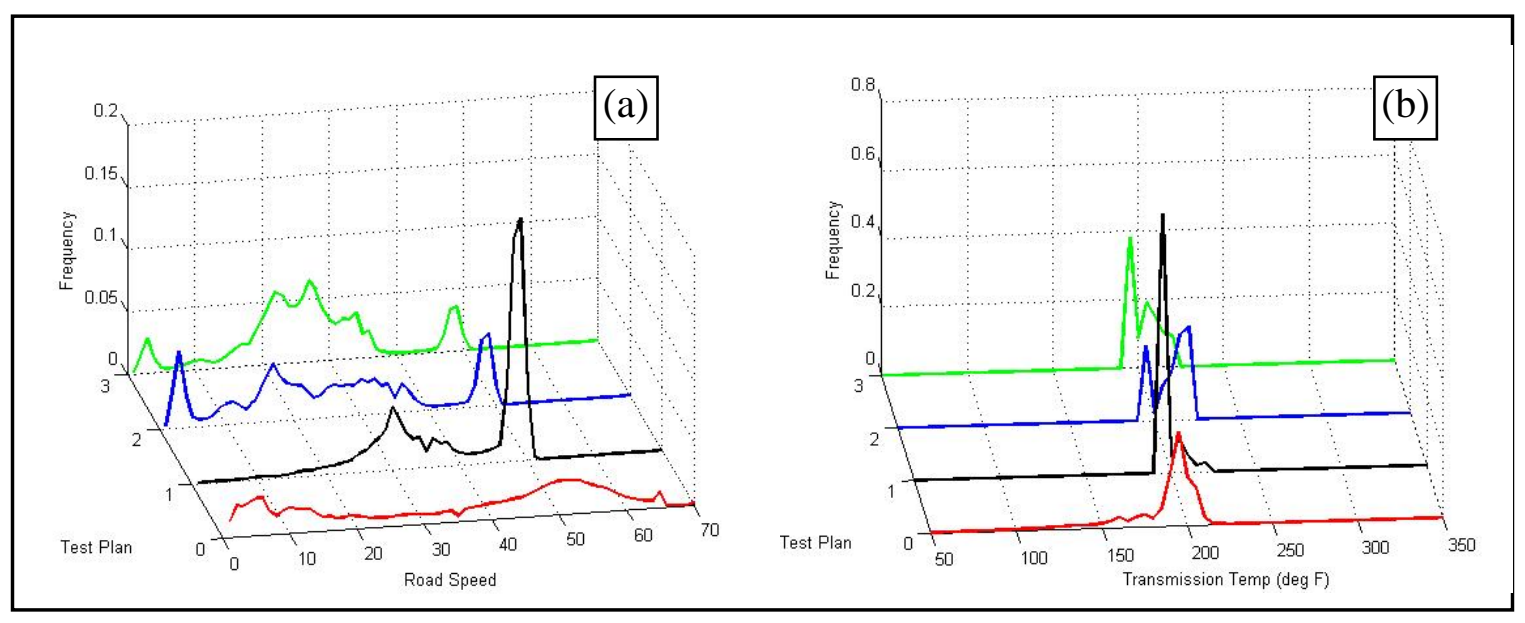

Figure 2. The combined distributions of different test plans for the M915 for (a) road speed distribution and (b) transmission temperature distribution. Test plan 0 (red) is the operational environment; test plan 1 (black), the standard M915 test plan; test plan 2 (blue), the singleobjective result; and test plan 3 (green), the dual-objective formulation.

Next, a dual-objective formulation was developed that included both the road speed distribution and the transmission temperature distribution, which had been identified as a second important behavior. The set of non-dominated solutions was generated by setting an upper bound $k$, requiring that $f_{2}(W) \leq k$, and then minimizing $f_{1}(W)$ subject to that constraint. Changing the value of $k$ generated different non-dominated solutions. The road speed error function remained significantly lower than the transmission temperature error function for the entire set of nondominated Pareto solutions.

After inspecting and discussing the results, the key decision-makers chose a solution that favored the transmission temperature error. The decision was based on the realization that the road speed error varied little and was significantly lower than the transmission temperature error, 
which displayed greater variation. In this particular case, the transmission temperature error can be minimized without significantly increasing the road speed error. The chosen Pareto solution was then converted into distances for the road course test matrix, as shown in Table 4. The resulting road speed and transmission temperature profiles are shown in Figure 2. From those profiles, it is clear that although the aggregate behavior distribution from the dual-objective optimal plan does not match the operational environment distribution closely, it is more accurate than the aggregate behavior distribution from the standard plan.

Many of the operating concerns for the M915 were also expressed in regard to the HMMWV. Road speed was again deemed the most significant behavior. Existing facility and operational environment data sets recorded for the HMMWV for this behavior were used in the optimization model to create a more relevant test plan. The resulting HMMWV optimal road course test plan and error value are shown in the second data column of Table 5. In that plan, the vehicle spends more time traveling at moderate speeds. Figure 3(a) shows the road speed distributions for the operational environment, the standard HMMWV test plan, and the two optimal plans. It is evident that the aggregate behavior distribution from the optimal plan does not match the operational environment distribution closely, but it is much closer than the aggregate behavior distribution from the standard plan (Test Plan 1).

Table 5. Comparison of the standard, single-objective optimal, and dual-objective optimal road course test plans for the HMMWV.

\begin{tabular}{|l|c|c|c|}
\hline \multirow{2}{*}{ Test Course } & \multicolumn{3}{|c|}{ Distance per course, km (mi) } \\
\cline { 2 - 4 } & $\begin{array}{c}\text { Standard } \\
\text { Plan }\end{array}$ & $\begin{array}{c}\text { Single-objective } \\
\text { Optimal Plan }\end{array}$ & $\begin{array}{c}\text { Dual- } \\
\text { objective } \\
\text { Optimal Plan }\end{array}$ \\
\hline Paved & $\mathbf{7 2 4 ( 4 5 0 )}$ & $\mathbf{5 4 6 ( 3 4 0 )}$ & $\mathbf{5 9 5 ( 3 7 0 )}$ \\
\hline Secondary Roads & $\mathbf{7 2 4 ( 4 5 0 )}$ & $\mathbf{2 7 4 ( 1 7 0 )}$ & $\mathbf{9 8 2 ( 6 1 0 )}$ \\
\hline MTA BB/G & $724(450)$ & & \\
\hline CTA-C & & $274(170)$ & $982(610)$ \\
\hline Cross-Country & $\mathbf{1 6 1 ( 1 0 0 )}$ & $\mathbf{7 8 9 ( 4 9 0 )}$ & $\mathbf{3 2 ( 2 0 )}$ \\
\hline PTA-1 & & $459(285)$ & $32(20)$ \\
\hline PTA-2 & $80(50)$ & $8(5)$ & \\
\hline CTA B & $81(50)$ & $322(200)$ & \\
\hline Total & $\mathbf{1 6 0 9 ( 1 0 0 0 )}$ & $\mathbf{1 6 0 9}(\mathbf{1 0 0 0 )}$ & $\mathbf{1 6 0 9 ( 1 0 0 0 )}$ \\
\hline Error (norm) & $\mathbf{0 . 3 0 4}$ & $\mathbf{0 . 1 7 4}$ & $\mathbf{0 . 1 9 3}$ \\
\hline
\end{tabular}




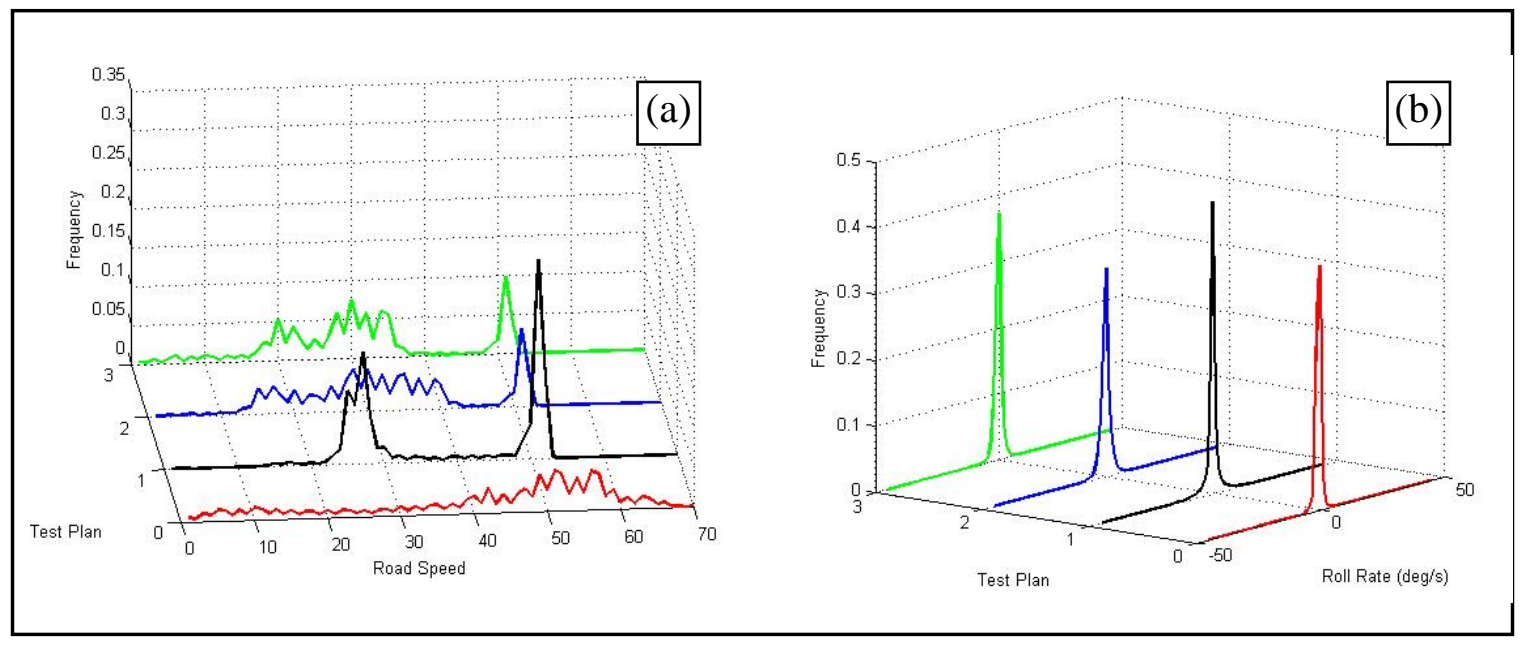

Figure 3. The combined distributions of different test plans for the HMMWV for (a) road speed distribution and (b) roll rate distributions. Test plan 0 (red) is the operational environment; test plan 1 (black), the standard HMMWV test plan; test plan 2 (blue), the single-objective result; and test plan 3 (green), the dual-objective formulation.

Next, a dual-objective formulation was examined that incorporated the distributions for road speed and roll rate, which was identified as a second important behavior. As with the M915, calculations yielded different non-dominated solutions. The road speed error function had approximately even trade-offs compared to the roll rate error function. After inspecting and discussing the results, the key decision-makers decided to choose a compensating solution that minimized the roll rate behavior error. The decision was based on mounting concerns regarding vehicle rollover accidents and the hope that new test plans-optimized for roll rate behavior and relevant to theatre operations - could help eliminate problems in the field. In this particular case, the roll rate error can be minimized without significantly increasing the road speed error. This solution was converted into distances for the road course test matrix, as shown in Table 5 . The resulting road speed and roll rate distributions for each road course test plan are provided in Figure 3.

\section{SUMMARY AND CONCLUSIONS}

This study presents an optimization approach to plan endurance tests when a combination of existing test facilities (which provide different test settings) must be used to replicate an operational environment. The optimization approach minimizes the difference between system behavior in the operational environment and the aggregate system behavior in the test plan. This approach has been used to create endurance test plans for two military vehicles.

The use of optimization is a significant change in the process of creating a detailed test plan. Traditionally, existing test plans have been reused without being changed to reflect a new operational environment. The optimization approach does require data about system behavior in the new operational environment. If the operational environment changes and new behavior data is acquired, the optimization model can be used again to design an updated test plan.

In general, this approach can be applied in planning any type of endurance test that must use a combination of existing test facilities, as long as data about the behavior in each facility and in the operational environment is available (or can be estimated with reasonable accuracy). 


\section{ACKNOWLEDGEMENTS}

The authors appreciate the support and assistance of the following personnel at the U.S. Army Aberdeen Test Center: Col. John P. Rooney, Commander; John Wallace, technical director; Gregory Schultz; and William Connon.

\section{REFERENCES}

1. Blanchard, Benjamin S., and Walter J. Fabrycky. 1998. Systems Engineering and Analysis. Upper Saddle River: Prentice Hall.

2. Hoy, Timothy W. 2007. Transformation Plans for Optimizing Military Vehicle Testing. MS Thesis, University of Maryland, College Park. http://hdl.handle.net/1903/6996.

3. Kouta, R., and D. Play. 2006. Definition of correlations between automotive test environments through mechanical fatigue damage approaches. Journal of Automobile Engineering 220:1691-1709.

4. Huizinga, A. T. M. J. M., M. A. A. Van Ostaijen, and G. L. Van Oosten Slingeland. 2002. A practical approach to virtual testing in automotive engineering. Journal of Engineering Design 13:33-47.

5. Scott, Michael J., and Erik K. Antonsson. 2005. Compensation and weights for trade-offs in engineering design: beyond the weighted sum. Transactions of the ASME: Journal of Mechanical Design 127:1045-1055.

6. Test Operation Procedure 1-1-011. 1981. Vehicle Test Facilities at Aberdeen Proving Ground. United States Army Test and Evaluation Command.

7. Department of Defense Directive 5000.1. 2003. The Defense Acquisition System. Under Secretary of Defense for Acquisition, Technology and Logistics.

8. Department of Defense Instruction 5000.2. 2003. Operation of the Defense Acquisition System. Under Secretary of Defense for Acquisition, Technology and Logistics.

\section{ABOUT THE AUTHORS}

Timothy W. Hoy is a mechanical engineer at the U.S. Army Aberdeen Test Center located at Aberdeen Proving Ground, Maryland. He serves as a test director on the Tactical Wheeled Vehicles Team of the Automotive Directorate, managing and directing endurance, performance, and safety testing on light, medium, and heavy military vehicles and supporting equipment. He earned a BS in mechanical engineering in 2004 and an MS in mechanical engineering in 2007, both from the University of Maryland. His thesis evaluated transformation plans for optimizing military vehicle testing.

Jeffrey W. Herrmann is an associate professor at the University of Maryland, College Park, where he holds a joint appointment with the Department of Mechanical Engineering and the Institute for Systems Research. He is a member of INFORMS, ASME, IIE, SME, and ASEE. Dr. Herrmann earned a BS in applied mathematics from Georgia Institute of Technology and a $\mathrm{PhD}$ in industrial and systems engineering from the University of Florida. His publications cover topics in engineering design, product development, manufacturing systems, and health care operations. His current research interests include health care operations research, production scheduling, and engineering design decision-making.

Contact author: Jeffrey W. Herrmann, Department of Mechanical Engineering, 2181 Martin Hall, University of Maryland, College Park, MD 20742 USA. 